\title{
Overcoming the Intrinsic Gefitinib-resistance via Downregulation of AXL in Non-small Cell Lung Cancer
}

\author{
Inae Jeong*, Jayoung Song*, Song Yi Bae, Sang Kook Lee \\ College of Pharmacy, Seoul National University, Seoul, Korea
}

\begin{abstract}
Background: Resistance to epidermal growth factor receptor tyrosine kinase inhibitors (EGFR-TKIs), such as gefitinib, is a limited factor in the treatment of non-small-cell lung cancer (NSCLC) patients. Therefore, ongoing studies are trying to identify EGFR-TKIs-resistant mechanisms and to discover novel therapeutic strategies and targets for NSCLC treatment.

Methods: In the present study, the possibility of overcoming intrinsic gefitinib-resistance was examined by regulating the expression of AXL. A natural product-derived antitumor agent, yuanhuadine (YD) was employed to modulate the expression of AXL in the cells. Results: Treatment with YD effectively downregulated AXL expression in AXL-overexpressed gefitinib-resistant H1299 cells. The combination of gefitinib and YD exhibited a synergistic grwoth-inhibitory activity in H1299 cells by downregulation of AXL expression.

Conclusions: Based on these findings, AXL was found to be a promising therapeutic target to overcome the intrinsic resistance to gefitinib in NSCLC. Furthermore, YD is able to effectively regulate the expression of AXL and thus it may be applicable as a potential lead compound for the treatment of gefitinib-resistant NSCLC.
\end{abstract}

(J Cancer Prev 2019;24:217-223)

Key Words: axl receptor tyrosine kinase, Non-small-cell lung cancer, Gefitinib, Yuanhuadine, Drug resistance

\section{INTRODUCTION}

Lung cancer is the most common type of cancer associated deaths worldwide [1]. In general, lung cancer is mainly categorized into two groups: non-small-cell lung cancer (NSCLC) and small-cell lung cancer (SCLC). Among these, NSCLC accounts for approximately $80 \%$ to $85 \%$ of all lung cancers, and $40 \%$ to $50 \%$ of NSCLC patients exhibit advanced Stage IV NSCLC at the time of diagnosis, and the five-year survival rate remains less than $1 \%$ [2]. For decades, the treatement options for NSCLC have been surgery, radiation therapy and chemotherapy. Although surgery is still the first-line therapy in early stage disease, it is not suitable for advanced or metastatic NSCLC. Therefore, platinum-based chemotherapy has been served as the standard treatment for advanced NSCLC. In this case, to increase the response rate, platinum agents, such as cisplatin and carboplatin, have been used in combination with other antitumor agents including paclitaxel, docetaxel, gemcitabine, vinorelbine and irinotecan $[3,4]$. However, the treatment outcomes for the patient are not satisfactory with various side. In addition, intrinsic and acquired resistance to the drug also limits its applications [5-7].

Currently, targeted therapy is mainly applied as one of the first-line therapies in Stage IV NSCLC. Since epidermal growth factor receptor (EGFR) is mutated and overexpressed in the majority of NSCLC which is associated with poor prognosis, the EGFR tyrosine kinase inhibitors (TKIs) have been developed as targeted chemotherapeutic agents against NSCLC [8]. These targeted therapies have significantly improved for the survival of advanced NSCLC patients. However, since 2005, the acquired resistance has been observed in NSCLC patients treated with EGFR-TKIs [9]. Recent studies have revealed that the resistance to EGFR-TKIs has been highly associated with the secondary

Received November 15, 2019, Revised December 2, 2019, Accepted December 5, 2019

Correspondence to: Sang Kook Lee

E-mail: sklee61@snu.ac.kr, ORCID: Sang Kook Lee, https://orcid.org/0000-0002-4306-7024

*These authors contributed equally to this work.

Copyright (C) 2019 Korean Society of Cancer Prevention

(c) This is an Open Access article distributed under the terms of the Creative Commons Attribution Non-Commercial License (http://creativecommons.org/licenses/by-nc/4.0) which permits unrestricted non-commercial use, distribution, and reproduction in any medium, provided the original work is properly cited. 
mutation in EGFR (T790M), overexpression MET kinase and activation of the NF- $\kappa B$ pathway [9-13]. Activation of the AXL, the receptor tyrosine kinase, has also been reported as a resistance mechanism of EGFR-TKIs in NSCLC [14,15].

AXL is a member of the TAM receptor tyrosine kinase family (Tyro-3, AXL, and MER). Growth-arrest-specific 6 (Gas6) and Protein S are the ligands for the TAM receptors, and Gas6 has the highest affinity for AXL $[16,17]$. AXL signaling is associated with cell survival, proliferation, invasion, metastasis, migration and anti-apoptotic effects $[18,19]$. AXL activation also affects the phosphoinositide 3-kinase (PI3K)/AKT, STAT3 and mitogen-activated protein kinase signaling pathways [20-22].

In the present study, we tried to elucidate whether the intrinsic resistance to gefitinib, the first-generation of EGFR-TKI, is able to be overcomed by downregulation of AXL. We employed the H1299 NSCLC cell line which exhibits high expression of AXL and thus assumed to be intrisinc resistance to gefitinib. In addition, yuanhuadine (YD), a daphnane-type diternoid antitumor agent, was used to regulate the expression of AXL based on the previous study which YD effectively degrades AXL levels in NSCLC cells [23].

\section{MATERIALS AND METHODS}

\section{Cell lines, reagents, and antibodies}

The H1299 cell, human lung cancer cell, was provided by the Korean Cell Line Bank (Seoul, Korea). The cell line was cultured in RPMI 1640 mediun supplemented with 10\% FBS and antibioticsantimycotics (100 units/mL penicillin G sodium, $100 \mathrm{mg} / \mathrm{mL}$ streptomycin, and $250 \mathrm{ng} / \mathrm{mL}$ amphotericin B). The cells were incubated at $37^{\circ} \mathrm{C}$ and $5 \% \mathrm{CO}_{2}$ in a humidified atmosphere.

YD (purity $>98.5 \%$ ) was isolated and identified from a $\mathrm{CHCl}_{3-}$ soluble fraction of the flower buds of Daphne genkwa, as described previously [24]. Cycloheximide (CHX) was purchased from A.G. Scientific (San Diego, CA, USA). Gefitinib was purchased from Selleckchem (Houston, TX, USA).

Antibodies against AXL and $\beta$-actin were obtained from Santa Cruz Biotechnology (Santa Cruz, CA, USA).

\section{Cell proliferation assay}

Cells were seeded in 96-well plates at a density of $5 \times 10^{3}$ cells/well and treated with various concentrations of test compounds. After incubation, cells were fixed with $10 \%$ trichloroacetic acid solution for 30 minutes at $4^{\circ} \mathrm{C}$, washed 5 times with tap water, and dried in the air. Cells were stained with $0.4 \%$ sulforhodamine B (SRB) in $1 \%$ acetic acid solution for 30 minutes at room temperature. After washing unbound dye and drying, stained cells were dissolved in $10 \mathrm{mM}$ Tris ( $\mathrm{pH} \mathrm{10.0),} \mathrm{and}$ absorbance was measured at $515 \mathrm{~nm}$. Cell viability was calculated by comparison with absorbance of vehicle-treated control group. The $\mathrm{IC}_{50}$ value, the concentration for $50 \%$ cell survival, was determined by non-linear regression analysis using Table curve 2D v5.01 (Systat Software Inc., San Jose, CA, USA).

\section{Western blot analysis}

The cells were lysed through boiling in $2 \times$ sample loading buffer (250 mM Tris- $\mathrm{HCl} \mathrm{pH}$ 6.8, 4\% SDS, 10\% glycerol, 0.006\% bromophenol blue, $2 \% \beta$-mercaptoethanol, $50 \mathrm{mM}$ sodium fluoride, and $5 \mathrm{mM}$ sodium orthovanadate) and further incubated for 10 minutes at $100^{\circ} \mathrm{C}$. Equal amounts of protein were subjected to $8 \%$ to $10 \%$ SDS-PAGE and transferred onto polyvinylidene fluoride or polyvinylidene difluoride membranse (Millipore, Bedford, MA, USA). The blots were blocked with $5 \%$ bovine serum albumin (BSA) in TBS containing 0.1\% Tween-20 (TBST) for 1 hour at room temperature, and then incubated with primary antibodies in $2.5 \%$ BSA in TBST overnight at $4^{\circ} \mathrm{C}$. The membranes were washed three times with TBST and incubated with the corresponding secondary antibodies diluted in $2.5 \%$ BSA in TBST for 2 hours at room temperature. After washing three times with TBST, the membranes were exposed to enhanced chemiluminescence solution (Intron, Daejeon, Korea). The blots were detected with an LAS-4000 (Fuji Film Corp., Tokyo, Japan).

\section{Real-time PCR}

The total RNA from the cells were extracted with TRI reagent (Invitrogen, Carlsbad, CA, USA), and $1 \mu \mathrm{g}$ of total RNA was reverse-transcribed using a Reverse Transcription System (Promega, Madison, WI, USA) according to the manufacturer's instructions. Real-time PCR was conducted using $\mathrm{iQ}^{\mathrm{TM}} \mathrm{SYBR}^{\circledR}$ Green Supermix (Bio-Rad, Hercules, CA, USA), according to the macufacturer's instructions. The conditions for the assay were the following: 20 seconds at $95^{\circ} \mathrm{C}, 40$ cycles of 20 seconds at $95^{\circ} \mathrm{C}$, 20 seconds at $56^{\circ} \mathrm{C}$, and 30 seconds at $72^{\circ} \mathrm{C}, 1$ minute at $55^{\circ} \mathrm{C}$. All of the experiments were performed in triplicate, and the analysis was performed through the comparative $\mathrm{C}_{\mathrm{T}}$ method using $\beta$-actin for normalization. The sequences of the primers are as follows; AXL, Sense: 5'-CGT AAC CTC CAC CTG GTC TC-3', Antisense: 5'-TCC CAT CGT CTG ACA GCA-3'. $\beta$-actin, Sense: 5'-AGC ACAATG AG ATC AAG AT-3', Antisense: 5'-TGT AAC GCA ACT AAG TCA TA-3'.

\section{Analysis of drug combination}

Cells were plated in 96-well plates $\left(5 \times 10^{4}\right.$ cells/well $)$ with 
various concentrations of test compounds. After 48 hours of incubation, the growth inhibition was measured using the SRB assay. The combined effect of the test compounds was analyzed by calculating the combination index $(\mathrm{CI})$ using the equation $\mathrm{CI}=$ $D_{1} /\left(D_{x}\right)_{1}+D_{2} /\left(D_{x}\right)_{2}$, where $D_{1}$ and $D_{2}$ are the concentrations of the combined compounds that achieve the expected effect, and $\left(D_{\mathrm{x}}\right)_{1}$ and $\left(D_{x}\right)_{2}$ are the concentrations that achieve similar effects when the compounds are used alone. In this study, 50\% inhibition was chosen as the effective level. The calculated CI was then compared to reported reference values [25].

\section{RESULTS}

1. The H1299 non-small-cell lung cancer cell line shows the intrinsic resistance to gefitinib

Recent studies have shown that the acquired resistance to gefitinib is highly correlated with the expression of AXL in NSCLC $[15,23]$. Therefore, we assumed that targeting the AXL kinase may also overcome the intrinsic resistance to gefitinib.

Primarily, to assess the correlation between AXL expression and gefitinib seneitivity, the $\mathrm{IC}_{50}$ values of gefitinib in four NSCLC cell lines, H1299, Calu-1, H292, and H1993, were evaluated (Fig. 1A). The H1299 and Calu-1 cells exhibit high expression of AXL, while the H292 and H1993 cells were shown with barely expression of AXL [23]. Four cell lines were treated with various concentrations of gefitinib for 48 hours. The growth inhibitory activity was determined by measuring the protein contents of cells using the SRB assay. The H1299 and Calu-1 cells were resistant to gefitinib ( $\mathrm{IC}_{50}>10 \mu \mathrm{M}$ ), but the H292 and H1993 cells were sensitive to gefitinib with the $\mathrm{IC}_{50}$ values of less than $1 \mu \mathrm{M}$. These data suggest that the H1299 and Calu-1 cells are relatively resistant to gefitinib.

To confirm the intrinsic resistance of H1299 cells to gefitinib, the $\mathrm{IC}_{50}$ values of gefitinib in H1299 cells for 48 hours and 72 hours were evaluated. As shown in Figure $1 \mathrm{~B}$, the $\mathrm{IC}_{50}$ values of gefitinib were over $50 \mu \mathrm{M}$ for 48 and 72 hours treatment. These findings are consistent with the previous reports and thus the H1299 cell line is considered an intrinsic resistant cell line to gefitinib [23]. Based on the results, further study was performed by employing the H1299 cells as an intrinsic resistance to gefitinib.

\section{Yuanhuadine downregulates $A X L$ expression in H1299 cells}

To further explore the effect of regulating AXL expression on the potential of cell proliferation, YD (Fig. 2A), a natural product-derived antitumor agent, was employed in the H1299 cells. YD effectively inhibited the proliferation of the H1299 cells with the $\mathrm{IC}_{50}$ values of $18 \mathrm{nM}$ for 48 hours and $15 \mathrm{nM}$ for 72 hours treatment, respectively (Fig. 2B). The Western blot analysis revealed that the expression of AXL was suppressed by the treatment of YD in a concentration-dependent manner (Fig. 2C). In addition, the mRNA expression of AXL was also downregulated by YD treatment in the H1299 cells (Fig. 2D). These data suggest that the downregulation of AXL expression is in part associated with the growth inhibtion of YD in the H1299 cells.

\section{Yuanhuadine accelerates the degradation of $A X L$ in $\mathrm{H} 1299$ cells}

To further elucidate whether YD is able to accelerate the degradation of AXL protein level in the H1299 cells, AXL protein
A

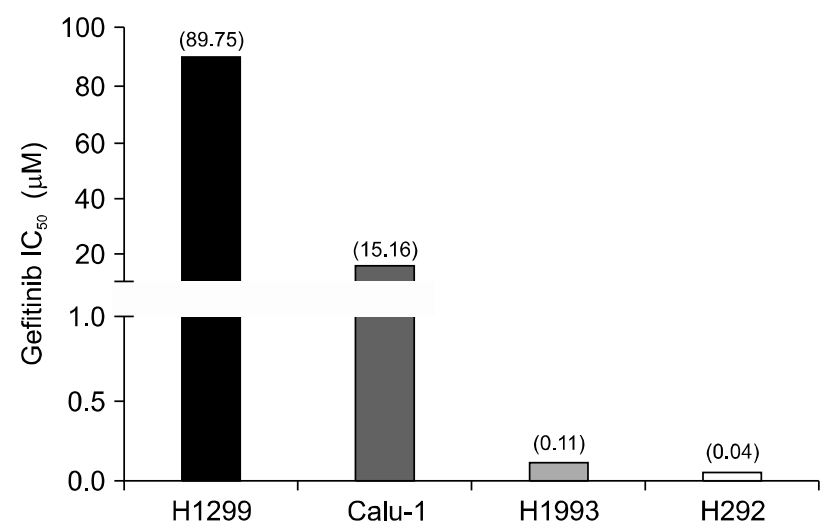

B

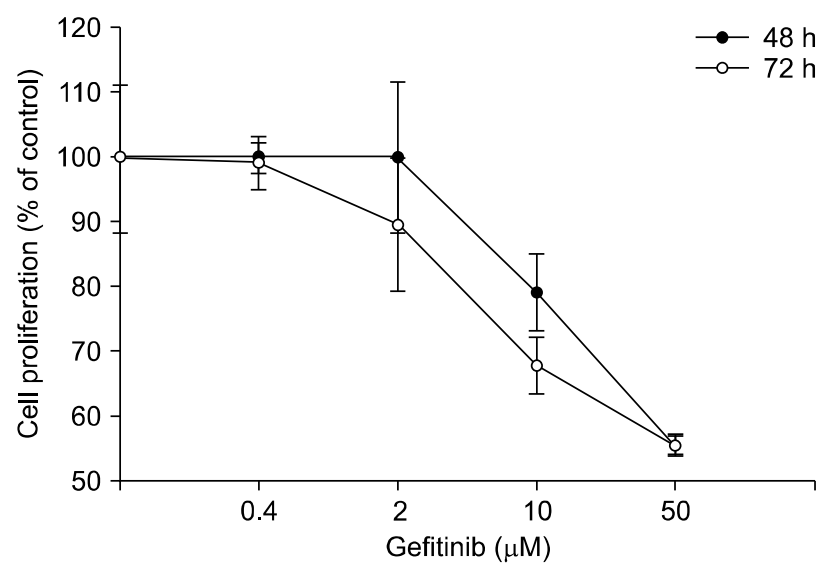

Figure 1. Cell proliferative activity of gefitinib in non-small-cell lung cancer cell lines. The cells were treated with gefitinib for 48 hours (A) or 48 and 72 hours (B). The cell proliferation was then determined by the sulforhodamine B assay as described in Materials and Methods. 
A

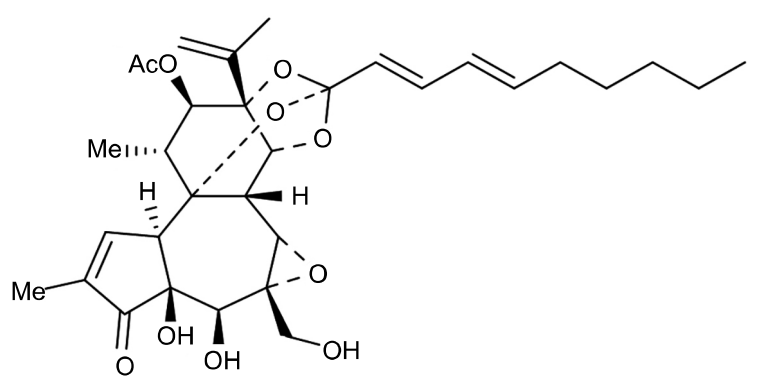

C

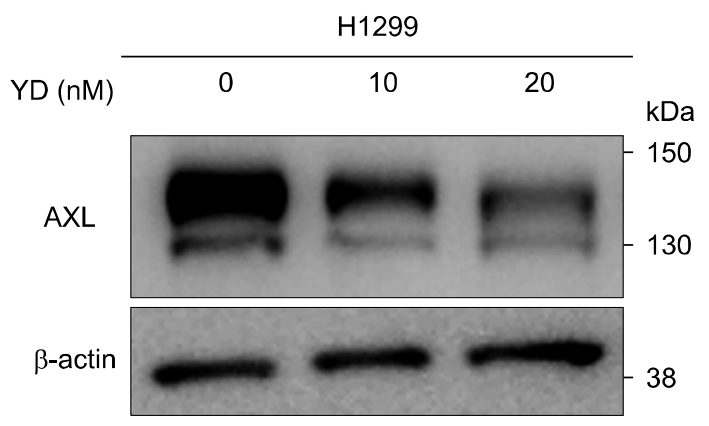

B
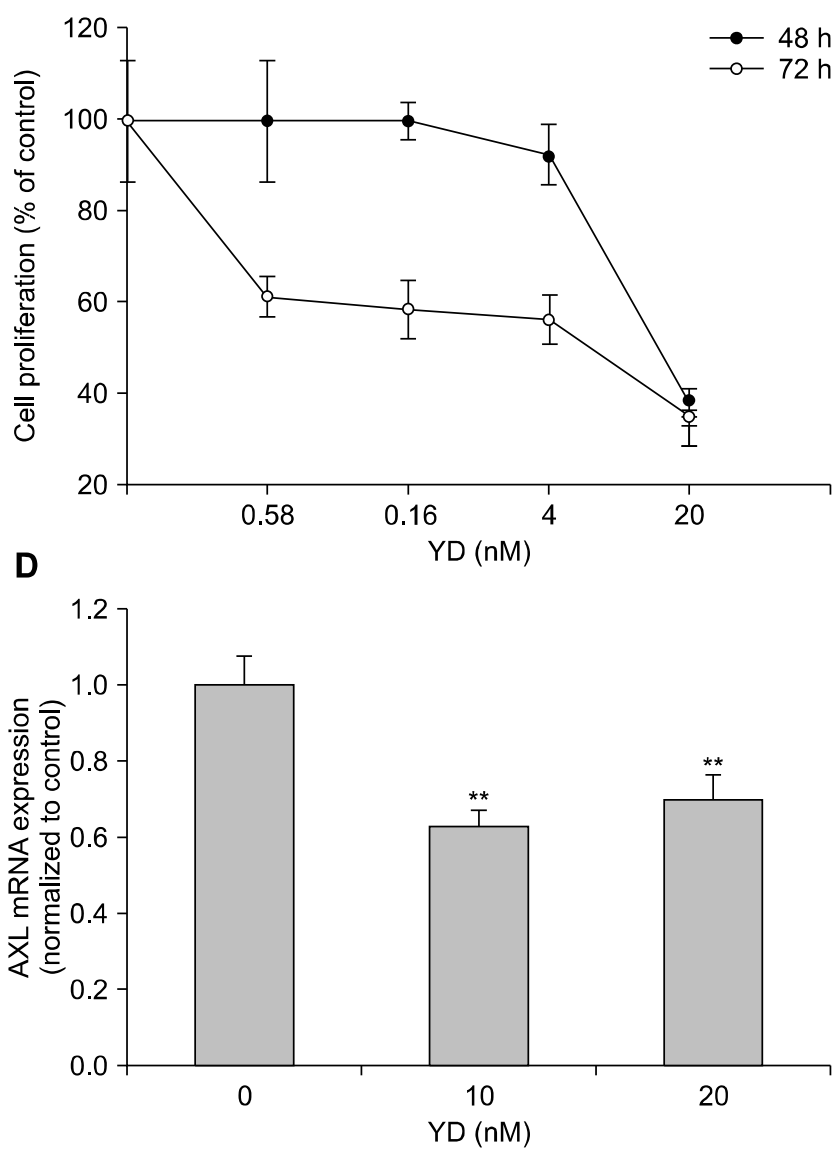

Figure 2. Downregulation of AXL expression by yuanhuadine (YD) in H1299 cell line. (A) The chemical structure of YD. (B) The effect of YD on cell proliferation in $\mathrm{H} 1299$ cells. The cells were treated with YD for 48 or 72 hours, and the cell growth was determined by the sulforhodamine B assay. (C) The effect of YD on the expression of AXL in H1299 cells. The cells were treated with the indicated concentrations of YD for 6 hours, and cell lysates were analyzed by Western blotting. $\beta$-actin was used as a loading control. (D) The effect of YD on the expression of AXL mRNA in H1299 cells. The mRNA expression was determined by real-time PCR, and $\beta$-actin mRNA levels were used for normalization. The data are presented as the mean $\pm \mathrm{SD}$. $* * P<0.01$ by $t$-test.

level was monitored in the cells after treatment with CHX, a protein synthesis inhibitor. The half-life of AXL degradation was approximately 3 hours in H1299 cells (Fig. 3A and 3B). However, the treatment of YD enhanced the degradation of AXL protein levels and the half-life of AXL degradation was shown to be less than 1 hour (Fig. 3C and 3D). These data suggest that YD is able to effectively accelerate the degradation of AXL protein in the H1299 cells which have high levels of AXL expression. The findings may have a potential to overcome the intrinsic resistance to gefitinib with the downregulation of AXL level in the highly AXL expressed NSCLC cells.

\section{Combination of gefitinib and yuanhuadine exhibits synergistic growth-inhibitory activity in H1299 cells}

To further explore whether the downregulation of AXL is able to recover the sensitivity of the growth-inhibitory activity of gefitinib against the H1299 cells, the cells were treated with different combinations of YD ( $5 \mathrm{nM}$ or $10 \mathrm{nM})$, an AXL degrader, and gefitinib $(6.25-50 \mu \mathrm{M})$ for 48 hours, and the cell proliferation was determined by the SRB assay. As shown in Figure 4, the combination of YD with gefitinib exhibits the enhanced growthinhibitory activity compared to gefitinib treatment alone in the H1299 cells. The CI value also showed the synergistic effect of YD and gefitinib combination on the grwoth-inhibitory activity of H1299 cells in all concentrations except $50 \mu \mathrm{M}$ gefitinib [25]. These data suggest that the synergistic growth-inhibtory activity of YD and gefitinib combination might be in part associated with the effective downregulation of AXL by YD in the cells.

\section{Downregulaton of $A X L$ overcomes the intrinsic resistance to gefitinib in $\mathrm{H} 1299$ cells}

To further confirm the involvement of AXL in the overcoming 
A

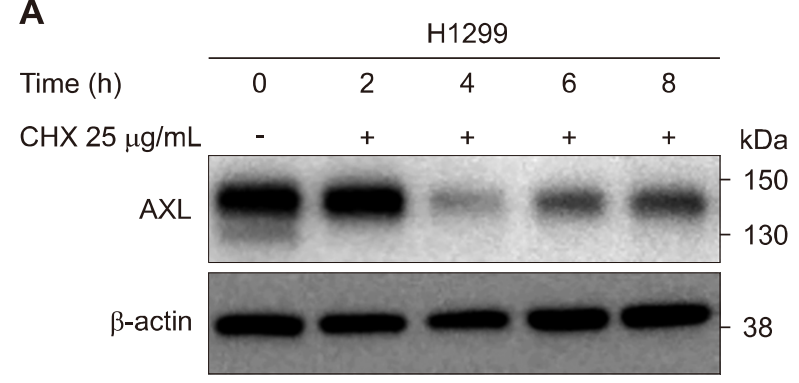

\section{C}

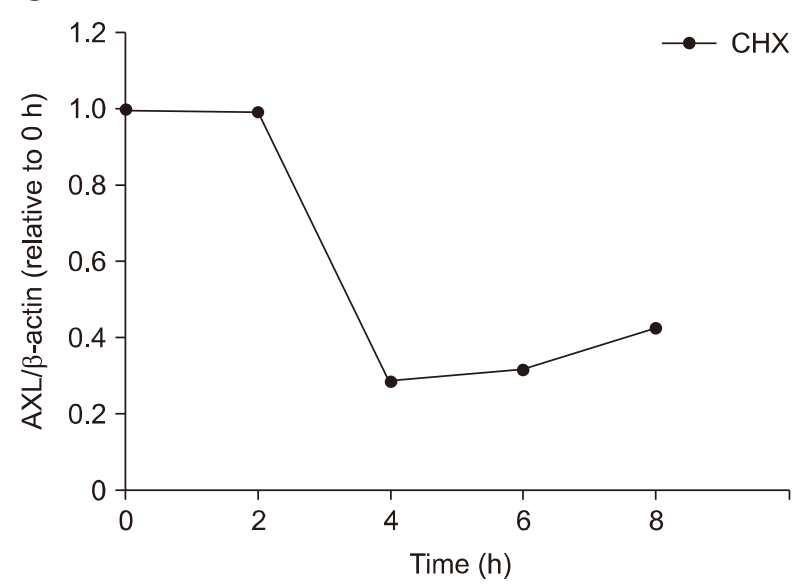

B

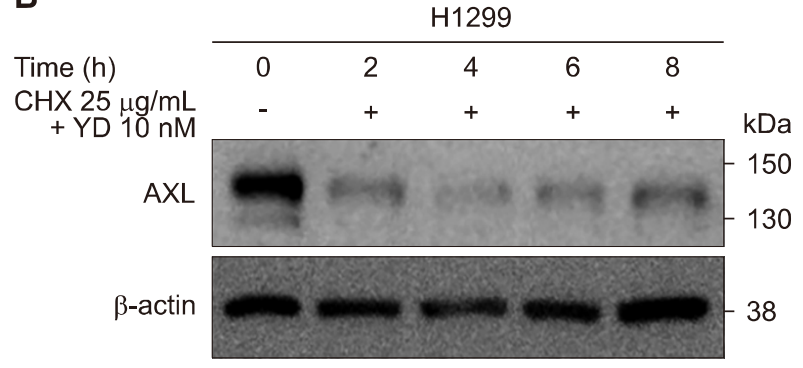

D

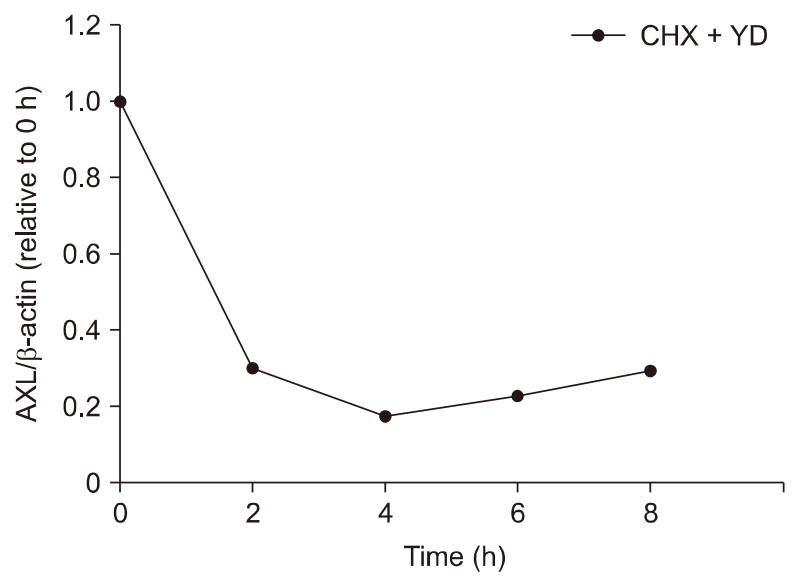

Figure 3. Enhancement of AXL degradation by yuanhuadine (YD) in $H 1299$ cells. (A, C) Cells were treated with $25 \mu \mathrm{g} / \mathrm{mL}$ cycloheximide (CHX) and $10 \mathrm{nM}$ YD for the indicated times. Cell lysates were analyzed by Western blot with an antibody against AXL. $\beta$-actin was used as a loading control. (B, D) AXL expression levels were quantifies by densitometry using ImageJ.

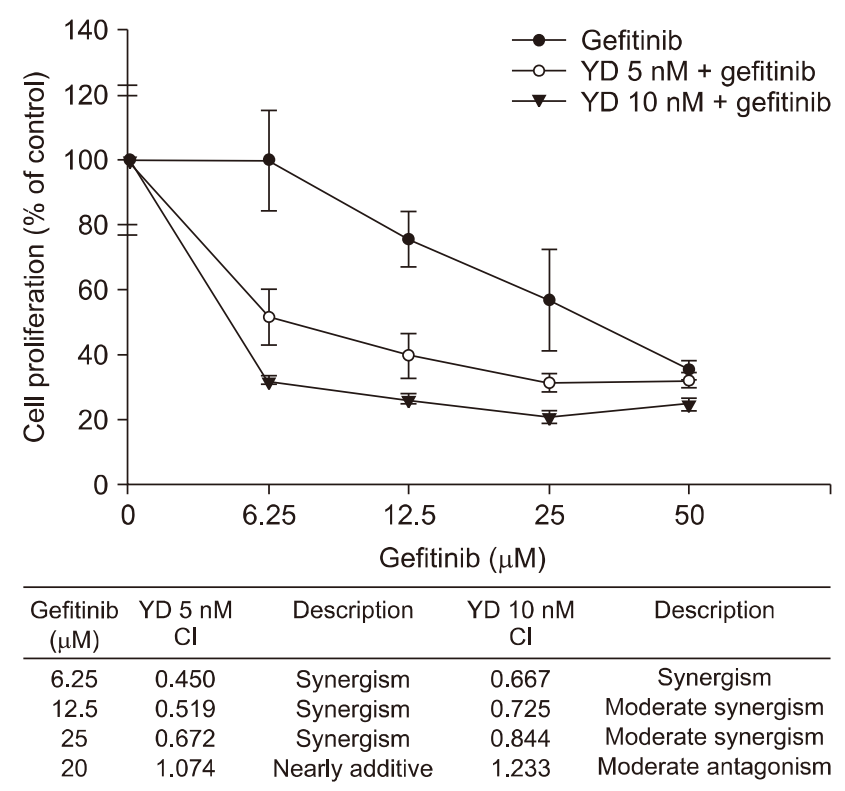

Figure 4. Effect of yuanhuadine (YD) and gefitinib in combination on cell proliferation in H1299 cells. The cells were treated with either YD alone or in combination with gefitinib for 48 hours, and then the cell proliferation was determined by the sulforhodamine $\mathrm{B}$ assay. $\mathrm{CI}$, combination index. intrinsic resistance to gefitinib, the $\mathrm{H} 1299$ cells were treated with YD (10 nM) and gefitinib (12.5 $\mu \mathrm{M})$, and the expression level of AXL was determined by the Western blot analysis. As shown in Figure 5, YD downregulated the expression of AXL, but gefitinib did not affect to the expression of AXL level. The combination of YD and gefitinib treatment, however, markedly enhanced the downregulation of AXL expression in the H1299 cells. These findings confirmed that the effective degradation of AXL level by antitumor agents in the highly AXL expressed NSCLC cells may ovecome the intrisic resistance to EGFR-TKIs in NSCLC.

\section{DISCUSSION}

High expression of AXL has been observed in varous types of cancer tissues and is considered as a poor prognostic biomarker $[26,27]$. Recent studies also reported that AXL activation is associated with TKI-resistance in various cancers, such as gastrointestinal stromal cancers, ovarian cancer, triple-negative breast cancer and chronic myeloid leukemia [28-30]. Based on the up-regulated AXL expression in H1299 NSCLC cells, we assumed that targeting AXL could be a promising therapeutic strategy to 


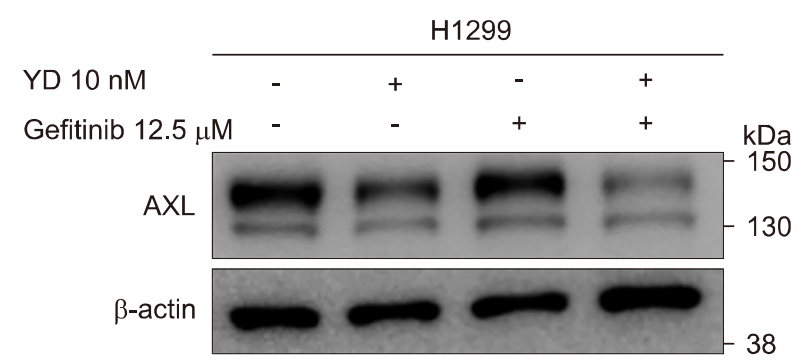

Figure 5. Downregulation of AXL expression in combination with yuanhuadine (YD) and gefitinib in H1299 cells. The cells were treated with YD $(10 \mathrm{nM})$ and/or gefitinib $(12.5 \mu \mathrm{M})$ for 6 hours, and the cell lysates were analyzed by Western blotting. $\beta$-actin was used as a loading control.

overcome intrinsic resistance to gefitinib in NSCLC.

YD is a daphnane-type diterpenoid isolated from the flower buds of Daphne genkwa (Thymelaeaceae) which is a medicinal plant widely distributed in Korea and China [24,31] Pharmacological studies exhibited the potent inhibitory activities of YD against DNA topoisomerase I and the growth of human leukemia and lung cancer cells [24,32,33]. In our previous study, we also reported that YD exerts a relatively strong selectivity for the growth inhibition of lung cancer cells compared to other solid cancer cell lines [34]. Recently, YD was also found to accelerate the degradation rate of full-length $\mathrm{AXL}$ in acquired gefitinib-resistant NSCLC cells [23].

In the present study, we futher extended to evaluate whether YD is able to effectively regulate the expression of AXL in the intrinsic gefitinib-resistant NSCLC cells. By employing H1299 NSCLC cells which show the intrinsic resistance to gefitinib, we found that YD effectively downregulated the AXL protein expression. The downregulation of AXL expression by YD was found to be associated with the enhancement of degradation of AXL in the H1299 cells. Based on the previous study, the mechanism by which YD induces AXL degaradation may be caused by the activation of presenilin-dependent regulated intramembrane proteolysis, one of degaradation mechanisms of receptor tyrosine kinase [23]. Furthemore, we found that the effective downregulation of AXL by YD recovered the sensitivity of gefitinib in the growth-inhibitory activity of H1299 cells. In addition, the combination of YD and gefitinib exerted the synergistic effect on the growth-inhibitory activity in the intrinsic gefitinib-resistant cells with AXL expression.

This present study provides a novel strategy to overcome the intrinsic resistance to gefitinib in NSCLC cells. The effective downregulation of AXL expression may be one of potential therapeutic approaches to overcome both intrinsic gefitinibresistance and acquired gefitinib-resistance NSCLC cells. On this line, YD might be a potential lead compound in the treatment of gefitinib-resistant NSCLC.

\section{ACKNOWLEDGMENTS}

This work was supported by the National Research Foundation of Korea Grants funded by the Korean Government (NRF2016M3A9B6903499).

\section{CONFLICTS OF INTEREST}

No potential conflicts of interest were disclosed.

\section{ORCID}

\author{
Sang Kook Lee \\ https://orcid.org/0000-0002-4306-7024
}

\section{REFERNCES}

1. Jemal A, Bray F, Center MM, Ferlay J, Ward E, Forman D. Global cancer statistics. CA Cancer J Clin 2011;61:69-90.

2. Ihde DC. Chemotherapy of lung cancer. N Engl J Med 1992; 327:1434-41.

3. Ramanathan RK, Belani CP. Chemotherapy for advanced nonsmall cell lung cancer: past, present, and future. Semin Oncol 1997;24:440-54

4. Shepherd FA. Treatment of advanced non-small cell lung cancer. Semin Oncol 1994:21(4 Suppl 7):7-18.

5. Wang D, Lippard SJ. Cellular processing of platinum anticancer drugs. Nat Rev Drug Discov 2005:4:307-20.

6. Schiller JH, Harrington D, Belani CP, Langer C, Sandler A, Krook J, et al. Comparison of four chemotherapy regimens for advanced non-small-cell lung cancer. N Engl J Med 2002;346:92-8.

7. Scagliotti GV, De Marinis F, Rinaldi M, Crinò L, Gridelli C, Ricci S, et al. Phase III randomized trial comparing three platinum-based doublets in advanced non-small-cell lung cancer. J Clin Oncol 2002;20:4285-91.

8. Brabender J, Danenberg KD, Metzger R, Schneider PM, Park J, Salonga $\mathrm{D}$, et al. Epidermal growth factor receptor and HER2-neu mRNA expression in non-small cell lung cancer is correlated with survival. Clin Cancer Res 2001;7:1850-5.

9. Pao W, Miller VA, Politi KA, Riely GJ, Somwar R, Zakowski MF, et al. Acquired resistance of lung adenocarcinomas to gefitinib or erlotinib is associated with a second mutation in the EGFR kinase domain. PLoS Med 2005;2:e73.

10. Engelman JA, Zejnullahu K, Mitsudomi T, Song Y, Hyland C, Park JO, et al. MET amplification leads to gefitinib resistance in lung cancer by activating ERBB3 signaling. Science 2007;316:1039-43.

11. Turke AB, Zejnullahu K, Wu YL, Song Y, Dias-Santagata D, Lifshits E, et al. Preexistence and clonal selection of MET amplification in EGFR mutant NSCLC. Cancer Cell 2010;17:77-88.

12. Bivona TG, Hieronymus H, Parker J, Chang K, Taron M, Rosell R, et al. FAS and NF-KB signalling modulate dependence of lung 
cancers on mutant EGFR. Nature 2011:471:523-6.

13. Arcila ME, Oxnard GR, Nafa K, Riely GJ, Solomon SB, Zakowski $\mathrm{MF}$, et al. Rebiopsy of lung cancer patients with acquired resistance to EGFR inhibitors and enhanced detection of the T790M mutation using a locked nucleic acid-based assay. Clin Cancer Res 2011;17:1169-80.

14. Byers LA, Diao L, Wang J, Saintigny P, Girard L, Peyton M, et al. An epithelial-mesenchymal transition gene signature predicts resistance to EGFR and PI3K inhibitors and identifies Axl as a therapeutic target for overcoming EGFR inhibitor resistance. Clin Cancer Res 2013;19:279-90.

15. Zhang $Z$, Lee JC, Lin L, Olivas V, Au V, LaFramboise T, et al. Activation of the AXL kinase causes resistance to EGFR-targeted therapy in lung cancer. Nat Genet 2012;44:852-60.

16. Hafizi S, Dahlbäck B. Signalling and functional diversity within the Axl subfamily of receptor tyrosine kinases. Cytokine Growth Factor Rev 2006;17:295-304.

17. Korshunov VA. Axl-dependent signalling: a clinical update. Clin Sci (Lond) 2012;122:361-8.

18. Lay JD, Hong CC, Huang JS, Yang YY, Pao CY, Liu CH, et al. Sulfasalazine suppresses drug resistance and invasiveness of lung adenocarcinoma cells expressing AXL. Cancer Res 2007;67:387887.

19. Linger RM, Keating AK, Earp HS, Graham DK. Taking aim at Mer and Axl receptor tyrosine kinases as novel therapeutic targets in solid tumors. Expert Opin Ther Targets 2010;14:1073-90.

20. Hasanbasic I, Cuerquis J, Varnum B, Blostein MD. Intracellular signaling pathways involved in Gas6-Axl-mediated survival of endothelial cells. Am J Physiol Heart Circ Physiol 2004:287:H1207-13.

21. Lee WP, Wen Y, Varnum B, Hung MC. Akt is required for Axl-Gas6 signaling to protect cells from E1A-mediated apoptosis. Oncogene 2002;21:329-36.

22. Hong CC, Lay JD, Huang JS, Cheng AL, Tang JL, Lin MT, et al. Receptor tyrosine kinase AXL is induced by chemotherapy drugs and overexpression of AXL confers drug resistance in acute myeloid leukemia. Cancer Lett 2008;268:314-24.

23. Bae SY, Hong JY, Lee HJ, Park HJ, Lee SK. Targeting the degradation of AXL receptor tyrosine kinase to overcome resistance in gefitinib-resistant non-small cell lung cancer. Oncotarget 2015; 6:10146-60

24. Hong JY, Nam JW, Seo EK, Lee SK. Daphnane diterpene esters with anti-proliferative activities against human lung cancer cells from Daphne genkwa. Chem Pharm Bull (Tokyo) 2010;58:234-7.

25. Chou TC. Theoretical basis, experimental design, and computerized simulation of synergism and antagonism in drug combination studies. Pharmacol Rev 2006;58:621-81.

26. Lee CH, Yen CY, Liu SY, Chen CK, Chiang CF, Shiah SG, et al. Axl is a prognostic marker in oral squamous cell carcinoma. Ann Surg Oncol 2012;19 Suppl 3:S500-8.

27. Shieh YS, Lai CY, Kao YR, Shiah SG, Chu YW, Lee HS, et al. Expression of axl in lung adenocarcinoma and correlation with tumor progression. Neoplasia 2005:7:1058-64.

28. Dufies M, Jacquel A, Belhacene N, Robert G, Cluzeau T, Luciano F, et al. Mechanisms of AXL overexpression and function in Imatinib-resistant chronic myeloid leukemia cells. Oncotarget 2011:2:874-85.

29. Mahadevan D, Cooke L, Riley C, Swart R, Simons B, Della Croce $\mathrm{K}$, et al. A novel tyrosine kinase switch is a mechanism of imatinib resistance in gastrointestinal stromal tumors. Oncogene 2007:26:3909-19.

30. Meyer AS, Miller MA, Gertler FB, Lauffenburger DA. The receptor AXL diversifies EGFR signaling and limits the response to EGFR-targeted inhibitors in triple-negative breast cancer cells. Sci Signal 2013;6:ra66.

31. Zhang S, Zhang F, Li X, Dong W, Wen L, Wang S. Evaluation of Daphne genkwa diterpenes: fingerprint and quantitative analysis by high performance liquid chromatography. Phytochem Anal 2007;18:91-7.

32. Zhan ZJ, Fan CQ, Ding J, Yue JM. Novel diterpenoids with potent inhibitory activity against endothelium cell HMEC and cytotoxic activities from a well-known TCM plant Daphne genkwa. Bioorg Med Chem 2005;13:645-55.

33. Zhang S, Li X, Zhang F, Yang P, Gao X, Song Q. Preparation of yuanhuacine and relative daphne diterpene esters from Daphne genkwa and structure-activity relationship of potent inhibitory activity against DNA topoisomerase I. Bioorg Med Chem 2006; 14:3888-95.

34. Hong JY, Chung HJ, Lee HJ, Park HJ, Lee SK. Growth inhibition of human lung cancer cells via down-regulation of epidermal growth factor receptor signaling by yuanhuadine, a daphnane diterpene from Daphne genkwa. J Nat Prod 2011;74:2102-8. 